\title{
Atividades Teórico-Práticas de Aprofundamento: enriquecimento da formação inicial por meio de um Sistema via $w e b$
}

\author{
Kennya Ferreira Silva Miranda - IFFluminense - kennyaferreira.kf@ gmail.com \\ Gilmara Teixeira Barcelos Peixoto - IFFluminense - gilmarab@iff.edu.br \\ Arilise Moraes de Almeida Lopes - IFFluminense - ariliselopes@ gmail.com
}

\begin{abstract}
Resumo: Atividades Teórico-Práticas de Aprofundamento (ATPA) devem ser cumpridas por licenciandos em atividades tais como: seminários e estudos curriculares; projetos de iniciação científica e docente; residência docente; monitoria e extensão; entre outras. Estas são previstas em resolução e têm como objetivo o enriquecimento da formação inicial. A carga horária mínima é de 200 horas. Para tanto, é importante que os alunos reflitam sobre a atividade realizada e, nesse sentido, as Tecnologias Digitais poderão dar suporte. Nesse contexto, foi desenvolvido um Sistema que, entre outros aspectos, possibilita o registro da relação entre a atividade realizada e a licenciatura em curso, por meio da escrita de um relatório. Este artigo tem por objetivo apresentar o sistema e a análise de dois testes desse sistema. Participaram dos testes alunos do $5^{\circ}$ período da Licenciatura em Letras do IFFluminense. A pesquisa teve caráter qualitativo e foi do tipo exploratória. Os instrumentos de coleta de dados foram observação, questionário e as postagens no Sistema ATPA. De forma geral, o sistema foi avaliado positivamente pelos licenciandos. A escrita do relatório possibilitou a reflexão sobre a atividade realizada e, consequentemente, o enriquecimento da formação inicial docente.
\end{abstract}

Palavras-chave: atividades teórico-práticas de aprofundamento, licenciatura, tecnologias digitais, sistema

\section{Theoretical-Practical Activities of Deepening: the enrichment of the initial teacher education through a web system}

Abstract: Theoretical-Practical Activities of Deepening (ATPA in Protuguese) must be accomplished by undergraduate students in activities such as: workshops and curricular studies; scientific initiation and teaching projects; teaching residency; monitoring and extension; and so on. These activities are set in resolution and their goal is the enrichment of early education. The minimum workload is 200 hours. Therefore, it is important that students reflect upon the activity performed and, for that matter, the Digital Tecnologies may support this. In this context, a system was developed that, among other aspects, enables the record of the relation between the activity performed and the course in progress, by writing a report. This article aims to present the system itself and the analysis of the two tests of two tests of this system. The 5th period of Letters undergraduate students participated in the tests. The research had a qualitative approach and exploratory nature. The data collection instruments used were observation, questionnaire and postings on the ATPA system. In general, the system was positively evaluated by the undergraduates. The writing of the report allowed the reflection on the activity performed and, as a consequence, the enrichment of the initial teacher education.

Keywords: theoretical-practical activities of deepening, licentiate, digital technologies, system.

\section{Introdução}

O ambiente escolar é afetado pelas mudanças que ocorrem na estrutura social do 
mundo contemporâneo, sendo importante que o professor, inserido nessa realidade volátil, adapte-se a esse novo contexto, variando sua prática (Clock et al., 2018). Nesse sentido, os professores das licenciaturas são grandes responsáveis por auxiliar os futuros docentes a desenvolverem a habilidade de "[...] pensar autônoma e sistematicamente" (Alarcão, 2010, p. 49). Dessa forma, as transformações necessárias no campo educacional tornar-se-ão possíveis quando o professor estiver em constante reflexão sobre sua formação e sobre sua prática (Corradini; Mizukami, 2011).

Além de refletir, o futuro professor mantém uma relação com diversos saberes docentes ao longo de sua formação e de sua ação de educador, os quais, segundo Tardif (2014), são saberes da formação profissional, saberes disciplinares, saberes curriculares e saberes experienciais. Esses saberes poderão ser construídos na própria instituição de formação inicial (Tardif, 2014) e poder-se-ão solidificar por meio das ações desenvolvidas nas aulas, dos conteúdos que constam nas matrizes curriculares, das experiências adquiridas no campo de estágio, bem como das atividades teórico-práticas de aprofundamento (ATPA).

As ATPA estão previstas na resolução No 2 de $1^{\circ}$ de julho de 2015 (Brasil, 2015), a qual define as Diretrizes Curriculares Nacionais para a formação inicial em nível superior (cursos de licenciatura, cursos de formação pedagógica para graduados e cursos de segunda licenciatura) e para a formação continuada. Esta resolução determina, entre outros aspectos, que os licenciandos devem cumprir uma carga horária de, no mínimo, 200 horas de participação nessas atividades que devem ser de interesse do aluno para enriquecimento curricular, por meio de seminários e estudos curriculares; projetos de iniciação científica e iniciação à docência; residência docente; monitoria e extensão; programas de mobilidade estudantil; atividades de comunicação e expressão, entre outras (Brasil, 2015). As ATPA, na resolução $\mathrm{N}^{\circ} 2$ de 19 de fevereiro de 2002 (Brasil, 2002) eram denominadas atividades acadêmico-científico-culturais (AACC).

A forma como essas atividades são realizadas pode contribuir para a ampliação do conhecimento geral dos licenciandos, suprindo lacunas que possam existir nas matrizes curriculares (Silva et al., 2012). Para que, de fato, essas atividades supram as lacunas dos cursos de licenciatura, enriqueçam a formação docente e não sejam cumpridas apenas por obrigação constante na lei, o aluno deve, além de realizá-las, refletir sobre elas e entender sua relação com a licenciatura em curso. Nesse sentido, as tecnologias digitais (TD) podem dar grandes contribuições ao processo de ensino e aprendizagem, bem como à reflexão dos alunos. Para tanto, é importante que o professor saiba utilizá-las de forma a conduzi-las a fim de promover novos conhecimentos e novos saberes (Kenski, 2003).

Diversas pesquisas (Domingues et al., 2017; Sonego et al., 2018 e Frizon et al. 2015) têm sido realizadas sobre enriquecimento da formação de professores com o auxílio das TD, o que ressalta a importância do tema.

Nesse contexto, realizou-se uma pesquisa, no âmbito do mestrado profissional em Ensino e suas Tecnologias que visou a investigar se e como os Institutos Federais do estado do Rio de Janeiro, nos cursos de licenciaturas, relacionam as ATPA à formação inicial de futuros professores, visando ao enriquecimento da sua prática docente. A partir dos resultados da pesquisa, foi desenvolvido um Sistema via web denominado ATPA que, entre outros aspectos, tem como foco a possibilidade de permitir ao licenciando refletir sobre a relação entre as ATPA realizadas e a licenciatura em curso. Assim, neste artigo, objetiva-se apresentar o sistema e a análise de dois testes desse sistema. Participaram dos testes alunos do $5^{\circ}$ período do curso em Licenciatura em Letras do Instituto Federal Fluminense (IFF).

Este artigo está estruturado em cinco seções, além desta introdução, na seção 
dois, apresenta-se uma breve revisão bibliográfica sobre formação inicial de professores e atividades teórico-práticas de aprofundamento. Já na seção três, apresentam-se os procedimentos metodológicos adotados na pesquisa. Em seguida, na seção quatro, o Sistema via web é descrito. Na seção cinco, os resultados encontrados são discutidos e, finalizando, na seção seis, são apresentadas algumas considerações sobre a pesquisa.

\section{Formação inicial de professores: atividades teórico-práticas de aprofundamento}

Para pensar em uma educação do futuro, é essencial refletir a educação como desenvolvimento de atividades que "[...] contribuam para a emancipação das pessoas" (Clock et al., 2018, p. 80). A fim de contribuir para formar seres humanos mais críticos e criativos, os formadores de professores têm a grande responsabilidade de possibilitar aos futuros docentes a reflexão sobre sua formação e sua prática (Alarcão, 2010).

$\mathrm{O}$ ato de refletir não deve ser feito de forma abstrusa, mas de forma clara para que aquele que reflete tenha consciência de suas interrogações e saiba estruturar sistematicamente seus saberes (Alarcão, 2010). Para a referida autora, existem diversas formas de desenvolver a capacidade de reflexão, sendo, uma delas, a narrativa.

A narrativa é o ato de escrever aquilo que está em nosso interior, aquilo que somente o escritor sabe na sua profundidade, o que verdadeiramente teve significado e sentido, extraindo o melhor aproveitamento da experiência vivenciada (Alarcão, 2010). "As narrativas serão tanto mais ricas quanto mais elementos significativos se registrarem" (Alarcão, 2010, p. 57). Nesse sentido, a autora afirma que essa estratégia deve ser adquirida ainda na formação inicial, uma vez que possibilitará essa prática se perpetuar por toda a sua profissão. A prática da narrativa ajudará o profissional a refletir sobre seu padrão de atuação, sobre sua vida profissional, sobre os aspectos alcançados e aspectos a melhorar, tornando-se uma ferramenta imprescindível ao professor reflexivo (Alarcão, 2010).

É no momento de reflexão que o futuro professor poderá tomar ciência dos saberes que são adquiridos no decorrer de sua formação. "Os saberes de um professor são uma realidade social materializada através de uma formação, de programas, de práticas coletivas, de disciplinas escolares [...]" (Tardif, 2014, p. 16).

Para Tardif (2014), os saberes podem ser provenientes da formação profissional, disciplinares, curriculares e experienciais. Os saberes da formação profissional são aqueles construídos dentro das instituições de ensino, são saberes das ciências da educação e da ideologia pedagógica que podem ser incorporados à prática dos professores. Já os saberes disciplinares são saberes sociais que as instituições selecionam para integrar a formação dos professores. Os saberes selecionados pelas instituições são categorizados e apresentados por meio de conteúdo, métodos, discursos e objetivos, essas formas de aplicação são chamadas de saberes curriculares. Por último, os saberes experienciais, que são aqueles adquiridos pela experiência que o futuro professor terá em sua prática profissional. Todos esses saberes poderão ser apropriados pelos alunos no decorrer de sua formação (Tardif, 2014) por meio de aulas, palestras, estágios, seminários, participação em bolsas de iniciação científica e várias outras atividades que demandem do aluno sua reflexão para a aprendizagem. Destaca-se, assim, a importância das ATPA (Brasil, 2015).

Dessa forma, para que haja o enriquecimento curricular, as ATPA devem ser cumpridas pelos alunos de forma que esses reflitam a relação das ATPA com sua formação inicial, aprofundando seu conhecimento. A escrita de um relatório pode favorecer essa reflexão sobre a participação na atividade realizada e contribuir para o aprimoramento de sua formação. Nesse sentido, as TD podem ser grandes aliadas, uma vez que será a partir delas que os alunos realizarão o relatório. 
As TD requerem novos ambientes de aprendizagem, possibilitando que esta aconteça a qualquer hora, em qualquer lugar dependendo da necessidade dos alunos (Kenski, 2003). Dessa forma, “[...] é necessário (re) pensar sobre o método de ensino e refletir sobre como estamos educando os professores que estão em serviço ou aqueles que ainda irão se formar nas universidades" (Valletta; Basso, 2018, p. 2). Além disso, essas tecnologias facilitam a interação entre os licenciandos e professores, entre outros aspectos (Domingues et al., 2017). Destaca-se, nesse contexto, o uso das TD para o acompanhamento das atividades realizadas.

O uso pedagógico das TD é ressaltado também na resolução $\mathrm{N}^{\circ} 2$ de 2015 (Brasil, 2015), na qual é previsto que, no decorrer do curso, o licenciando deve ser conduzido "[...] vi - ao uso competente das Tecnologias de Informação e Comunicação (TIC) para o aprimoramento da prática pedagógica e a ampliação da formação cultural dos (das) professores (as) e estudantes" (Brasil, 2015, p. 6). E, ainda, o artigo $8^{\circ}$ inciso $\mathrm{V}$ dessa resolução prevê que os licenciandos devem estar aptos, ao fim do curso, a "[...] relacionar a linguagem dos meios de comunicação à educação, nos processos didáticopedagógicos, demonstrando domínio das tecnologias de informação e comunicação para o desenvolvimento da aprendizagem" (Brasil, 2015, p. 8).

Corroborando essa ideia, Parcianello e Konzen (2011) alegam que, para se utilizarem as TD na educação, é recomendado que os licenciandos as conheçam e saibam utilizá-las em seu dia a dia, levando uma aprendizagem mais significativa aos seus alunos. Nessa vertente, a utilização de um Sistema via web para aprimorar o armazenamento, a discussão e a avaliação das ATPA poderão agregar valor ao processo de aprendizagem dos licenciandos.

\section{Procedimentos Metodológicos}

Com vista a avaliar o Sistema via web, bem como captar a percepção dos licenciandos quanto à importância da ATPA para o enriquecimento da prática docente, adotou-se uma abordagem qualitativa, realizando-se uma pesquisa exploratória. Esse tipo de pesquisa tem por objetivo aproximar o pesquisador de seu tema para formulação mais precisa da realidade e, geralmente, é acompanhado de pesquisas documental e bibliográfica (Gil, 2008). Dando continuidade à pesquisa exploratória, realizou-se a pesquisa documental, que, segundo Tozoni-Reis (2010), busca recolher informações sobre o fenômeno pesquisado em documentos oficiais.

Foram utilizados, como instrumentos de coleta de dados, a observação, o questionário e as postagens dos alunos no Sistema. Esse questionário contém doze perguntas abertas e fechadas, respondido após a experimentação do Sistema ATPA.

Este sistema foi desenvolvido com o intuito de facilitar o registro das atividades, incluindo a carga horária, bem como possibilitar a reflexão da relação da atividade realizada com a licenciatura do aluno. Durante e após seu desenvolvimento, foram realizados dois testes para verificar possíveis erros, tanto em relação à programação como aos processos/procedimentos que devem ser realizados para que o sistema atenda, satisfatoriamente, às necessidades dos usuários, que são os alunos dos cursos de licenciatura, e também aos objetivos dos profissionais responsáveis pela avaliação das ATPA nos institutos.

O primeiro teste ocorreu no dia 12 de dezembro de 2018, com duração de 1h40min e participaram todos os 22 licenciandos matriculados no componente curricular Diálogos com a escola campo I, em 2018-2, no curso de licenciatura em Letras: Português e Literaturas, ministrado pela primeira autora deste artigo. Inicialmente, as seções do sistema foram apresentadas, a seguir, cada licenciando fez o seu registro e cadastrou algumas atividades. Durante a realização dos cadastros das 
atividades, os participantes apresentavam, oralmente, as dúvidas e os problemas diagnosticados os quais foram analisados, e as alterações consideradas importantes feitas no sistema. Com a participação de 18 licenciandos e com a mesma duração do primeiro teste, realizou-se o segundo, no dia 26 de fevereiro de 2019. Nesse dia, os participantes puderam observar as alterações feitas no sistema e continuaram o cadastramento das atividades.

Em cada teste foi observado e analisado o desempenho do sistema, sua usabilidade, as reações dos alunos ao experimentá-lo e, também, as postagens feitas.

Apenas os 18 licenciandos participantes do segundo teste responderam ao questionário. Portanto, somente estes foram considerados para análise dos dados, os participantes foram nomeados $\mathrm{K} 1, \mathrm{~K} 2, \mathrm{~K} 3, \ldots, \mathrm{K} 18$ para que fosse assegurado o sigilo. Na seção seguinte, o Sistema via web é apresentado.

\section{Descrição do Sistema via web ATPA}

O Sistema via $w e b^{1}$ criado foi denominado ATPA. Segundo Sourcelab (2018, s.p.), sistemas via web “[...] são sistemas informatizados acessíveis através de um navegador ou de um aplicativo, via internet ou rede, capazes de processar informações em servidores para cumprir determinadas regras de negócio". O sistema ATPA visa a apoiar o armazenamento, a discussão, por meio dos relatórios, e as interações dos professores e/ou supervisores com os alunos e, também, possibilita a avaliação das ATPA realizadas, com vista ao enriquecimento da formação docente.

O Sistema ATPA foi planejado e elaborado por uma equipe multidisciplinar composta por duas pedagogas do Núcleo de Apoio à Prática Docente; uma professora da licenciatura que atua nos componentes curriculares da área de Educação; duas professoras pesquisadoras da área de formação de professores para uso pedagógico das TD e dois bolsistas alunos do curso superior de Bacharelado em Sistemas de Informação, as três professoras são as autoras deste artigo.

Para tanto, foi utilizada a linguagem de programação Ruby com o Framework Rails, comumente conhecida como Ruby on Rails, e, para o banco de dados, o MySQL. O desenvolvimento do sistema foi realizado após o levantamento dos requisitos necessários que foram obtidos a partir da análise de documentos normativos das ATPA nos institutos federais do estado do Rio de Janeiro.

O sistema possui perfil do aluno e área do administrador (supervisor das ATPA), as interfaces são semelhantes. A página inicial destina-se ao registro e login do aluno no sistema. A página que aparece após a efetivação do login nos dois perfis contém no centro um texto de apresentação do sistema e um menu lateral (Figura 1). O menu do supervisor possui todos os itens do perfil aluno acrescido pelo item "Usuários".

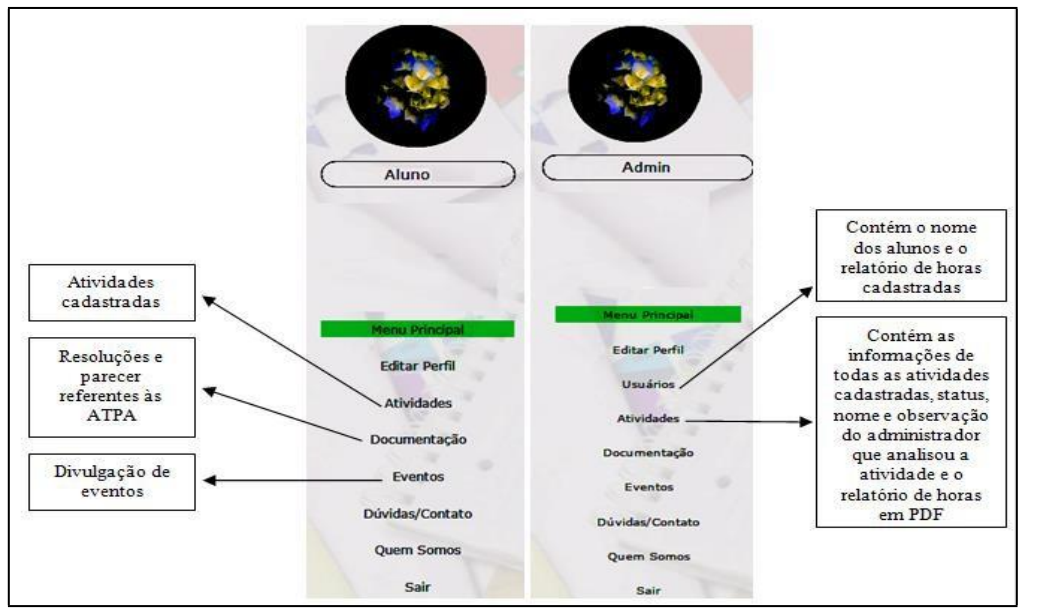

Figura 1- Menu da tela de apresentação dos perfis aluno e supervisor. 
$\mathrm{Na}$ área do aluno, ao acessar, no menu, o item "Atividades", aparecerá a tela denominada "Atividades Cadastradas" (Figura 2). Nela, os alunos poderão cadastrar as atividades; exibir o total de horas cadastradas; gerar relatório completo; voltar à página anterior, além de acessarem atividades já cadastradas, podendo filtrar uma atividade específica no campo procurar. Poderão, ainda, visualizar o nome e a observação do administrador que analisou a atividade.

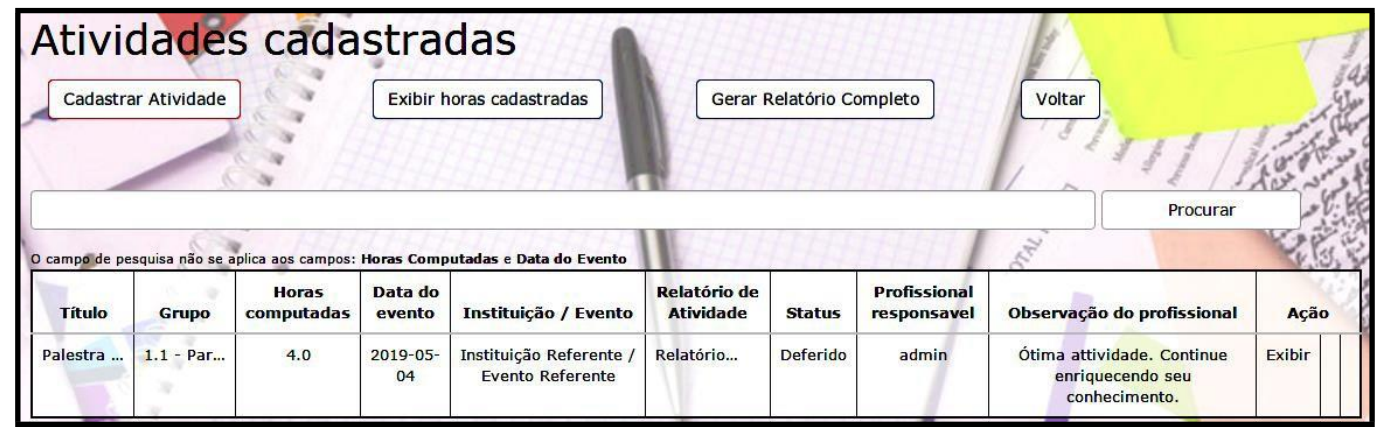

Figura 2- Atividades cadastradas.

Ao cadastrar uma atividade (Figura 3), o aluno deve preencher os dados, escolhendo o grupo ${ }^{2}$ em que essa atividade se encaixa. Além disso, o aluno deve fazer o upload do comprovante de participação no campo "Escolher arquivo" e, ainda, precisa escrever um relatório, destacando a relação da atividade realizada com a licenciatura em curso, sua importância e os aspectos positivos e negativos identificados para sua formação. Considera-se que o relatório é o diferencial do sistema, uma vez que permite ao aluno refletir e ressaltar em que a atividade contribuiu para o enriquecimento da sua formação inicial. Todas as informações cadastradas serão validadas, ou não, pelo supervisor, por meio do acesso pela área de administrador.

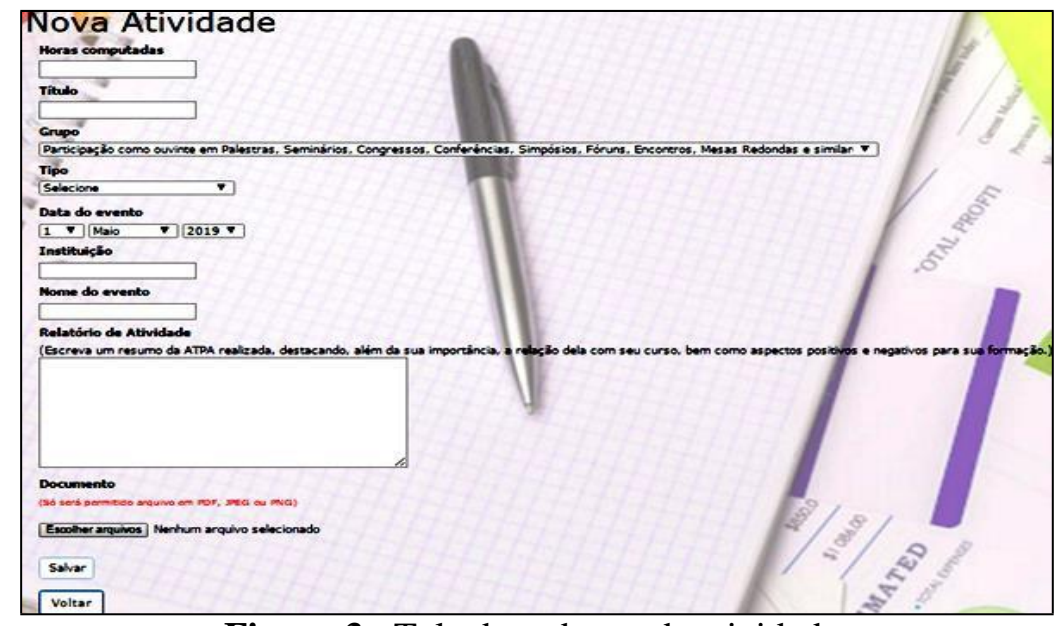

Figura 3 - Tela de cadastro da atividade.

$\mathrm{Na}$ área do administrador, no menu principal, há o botão de usuários, o qual encaminha para a página de acesso a todos os alunos cadastrados. Nessa página, o administrador poderá visualizar a foto, o nome, a matrícula, o curso de licenciatura, bem como uma tabela com a carga horária, referente às horas acadêmicas realizadas pelos alunos. Além dessa página citada, há, no menu principal, a aba "Atividades" a qual abrirá uma página em que está disponibilizado um quadro. Esse quadro apresenta uma linha de itens em que é possível observar campos que foram preenchidos pelos licenciandos, como o título, o grupo, as horas computadas, a data, a instituição/evento, o relatório de atividade, o nome do aluno, bem como campos preenchidos pelo administrador, como o status, o nome do profissional responsável (administrador), sua 
observação e sua ação. Nesse campo "ação", há um botão denominado "Analisar" que direcionará o usuário para a página "Analisando Atividade", em que o administrador poderá analisar os dados cadastrados pelos licenciandos. Além disso, é possível gerar, em PDF, a tabela de horas cadastradas.

O Sistema via web ATPA, apresentado nesta seção, é resultante dos dois testes realizados com os licenciandos. Os dados coletados, durante os testes, são apresentados na seção seguinte.

\title{
5. Resultados e discussão
}

Ressalta-se que antes da criação do sistema via web ATPA o registro, a avaliação e contagem das horas, no instituto em que o sistema foi experimentado, eram realizados manualmente. Além disso, não era exigida a entrega de relatório da atividade, fatos que destacam a importância do sistema para a formação de professores.

De maneira geral, durante a observação, foi notado que os licenciandos não tiveram dificuldades na utilização do Sistema via web. Além disso, notou-se que, no decorrer da elaboração dos relatórios, os licenciandos estavam entusiasmados com as lembranças que tinham dos eventos que haviam participado, comentando, oralmente, a relação dos temas das atividades com o que tinham estudado nas aulas. Ainda durante a escrita do relatório, os participantes comentaram que os temas Educação Inclusiva, Educação de Jovens e Adultos, entre outros, poderiam ser componentes curriculares. Isso sinaliza a importância da ATPA para o enriquecimento da matriz curricular, uma vez que algumas palestras, por exemplo, abordam assuntos novos para os alunos. Ao preencher as informações das atividades, observou-se que alguns alunos ficaram em dúvida sobre a que grupo pertenceria a atividade cadastrada. Essas foram sanadas pela professora e decorrem da falta de leitura dos documentos que regulam a ATPA no instituto.

Em relação às postagens no Sistema via web, contabilizaram-se 58 relatórios realizados pelos dezoito alunos que participaram dos testes. Alguns relatórios serão comentados a seguir. De forma geral, observou-se, por meio dos relatórios, que a ATPA contribui de forma positiva para a formação docente, enriquecendo alguns temas já estudados e complementando a matriz curricular do curso. O aluno K 17 expressou que a ATPA o levou a refletir sobre o curso que realiza.

\begin{abstract}
A relação dessa atividade com a minha formação é fazer desenvolver mais o meu desempenho como professor, bem como me levar a refletir sobre o ensino de Língua Portuguesa, de que maneira pode ser abordada. Além disso, foi-me importante esse evento no que diz respeito a conhecer mais sobre a própria língua [...] (Licenciando K7).
\end{abstract}

O trecho do relatório de K7 reforça o que ressalta Alarcão (2010) quando afirma que o ato de refletir sobre diversas atividades que realiza é algo que já está implícito no ser humano, entretanto esta se torna efetiva quando realizada em ambientes de liberdade e responsabilidade (Alarcão, 2010).

O licenciando K14 também cita a realização das ATPA como enriquecimento para a sua formação, uma vez que, ao participar do evento, pôde desenvolver sua criticidade. Sobre isso, Alarcão (2010) afirma que é preciso que o aluno dialogue com ele mesmo, com o outro e com a situação, que pode ser a ATPA. Dessa forma, atingirá um nível de explicação e criticidade para agir e falar com mais independência.

Esse minicurso foi de suma importância para minha formação como docente, pois me propiciou um olhar mais crítico e ao mesmo tempo mais valorizado em termos de educação e seus complementos essenciais (Licenciando K14). 
Ao final do segundo teste, os alunos responderam ao questionário. Esse questionário contém quatro partes. A primeira parte contém o termo de consentimento, a segunda, o perfil do aluno e informações sobre uso de sistemas via web; na terceira, é feita uma avaliação técnica e, por fim; na quarta parte, uma avaliação pedagógica.

Ao se questionar sobre o costume dos alunos ao utilizar sites, observou-se que eles têm habilidades nessa ação, uma vez que afirmaram saber fazer download de arquivo, cadastrar-se em sites, preencher formulários online, anexar arquivos, escanear documentos. Quanto à classificação da habilidade de uso de sites, cinco responderam ser ótima; dez, boa; e três disseram ser regular. Sendo assim, considerou-se que os sujeitos tinham condições de avaliar o sistema.

Ao se questionar quanto aos aspectos pedagógicos do Sistema via web, destacase que a maioria dos alunos avaliou as afirmações positivamente, uma vez que marcaram que concordam ou concordam parcialmente que o sistema apresenta informações claras, organizadas, encadeadas, segundo uma estrutura de fácil compreensão, apresenta redação adequada com linguagem didática e é motivador e engajador (Gráfico 1).

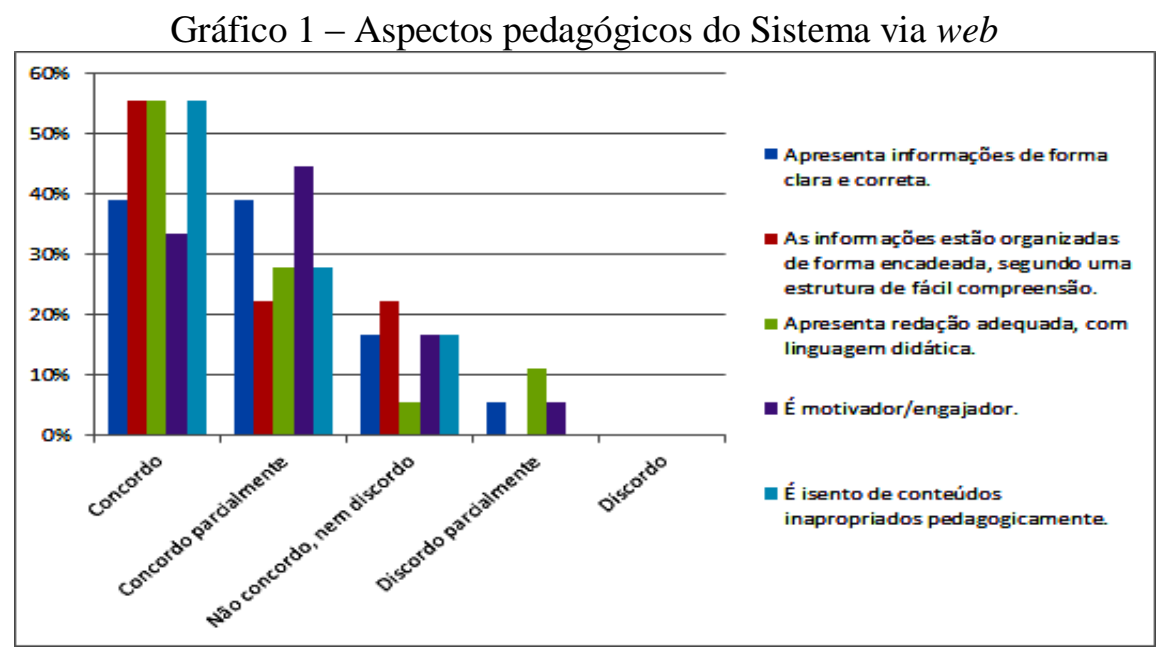

Fonte: Elaboração própria.

Questionou-se sobre os critérios de seleção das ATPA, diagnosticando-se que 9 alunos observam o local do evento; 10, a hora e a data do evento e pertinência do tema com futuras práticas docentes; 12 , a necessidade de completar as horas acadêmicas e 13, a pertinência do tema com o curso; mostrando, assim, que não se preocupam apenas em cumprir a carga horária destinada às ATPA. Essa observação vai ao encontro da afirmação de Silva et al. (2012) ao defender que as ATPA não sejam cumpridas apenas por recomendação da lei, mas sim que contribuam, ampliando o horizonte do conhecimento, fora de sala de aula, para as futuras práticas dos docentes.

Sobre a elaboração do relatório da ATPA realizada, por meio de um Sistema via $w e b$, vir a contribui para enriquecer a formação docente, quinze alunos responderam positivamente e os outros três negativamente. Foi solicitada a justificativa das respostas. Os três que responderam "Não" afirmaram apenas que não gostam destas atividades. A maioria dos licenciandos destacou que, ao elaborar o relatório, foi possível refletir sobre a ATPA realizada, percebendo sua importância para a formação docente, ampliando e enriquecendo os conhecimentos, contribuindo para que se tornem melhores profissionais, como se evidencia nas respostas de K8 e K16:

Fazer refletir sobre cada atividade que participei e as oportunidades que tive para ampliar o conhecimento (Licenciando K8).

Uma reflexão sobre a contribuição da atividade com a formação docente (Licenciando K16). 
Foi possível perceber que os alunos consideraram que elaborar um relatório sobre a ATPA em um Sistema via web auxilia-os a refletir sobre os saberes alcançados, permitindo relacioná-los com aqueles construídos no decorrer de sua formação.

Em relação aos saberes docentes (Tardif, 2014) alcançados no desenvolvimento da ATPA, a maioria, 12 alunos, afirmou que as atividades contribuíram para adquirir saberes experienciais, uma vez que tiveram a oportunidade de se relacionarem "[...] com professores experientes [...]" (Tardif, 2014, p. 52), entre outras justificativas. Os saberes da formação profissional e os saberes curriculares foram considerados por 9 alunos uma vez que o conhecimento é produzido no decorrer de sua formação e utilizado na prática docente e devem aprender para ensinar de acordo com os objetivos, métodos e conteúdos estabelecidos pelos programas escolares (Tardif, 2014), respectivamente. Já os saberes disciplinares foram listados, por 4 alunos, visto que os futuros professores devem se apropriar desses saberes para levar ensinamentos aos seus alunos (Tardif, 2014), nesse sentido os licenciandos complementam seus conhecimentos quando realizam as ATPA.

\section{Considerações finais}

Este trabalho apresentou a análise dos testes de um Sistema via web e sua influência na reflexão da relação entre as ATPA e a licenciatura em curso.

A avaliação técnica e pedagógica do sistema mostrou-se importante para validação de seu uso. Os licenciandos demonstraram muita satisfação e entusiasmo, dados os recursos disponíveis no sistema. Também, contribuíram muito para que fossem realizadas melhorias no sistema.

Além disso, o sistema via web possibilitou identificar que os objetivos das ATPA cadastradas pelos licenciandos foram alcançados. A elaboração do relatório foi importante para o diagnóstico desse resultado. O relatório contribuiu para a reflexão do aluno sobre a atividade realizada e relacioná-la com a licenciatura em curso, enriquecendo a formação inicial docente.

Os resultados aqui apresentados, mesmo que colaborem para armazenamento, discussão e avaliação das ATPA, não podem ser generalizados, uma vez que o sistema foi testado apenas em uma turma da licenciatura em Letras. Desse modo, para que haja outras visões e outras experiências, trabalhos futuros serão realizados. Sendo assim, os alunos do oitavo período da mesma licenciatura e no mesmo instituto experimentarão o sistema para mais uma análise. Posteriormente, todas as turmas dos cursos de licenciatura do instituto utilizá-lo-ão. Espera-se, dessa forma, contribuir para a formação de professores para além dos conteúdos previstos na matriz curricular.

\section{Notas de texto}

${ }^{1}$ Link do Sistema ATPA <http://atpa.centro.iff.edu.br/>.

2 No Instituto Federal Fluminense, em que ocorreram os testes do sistema, as ATPA devem ser realizadas considerando-se um quadro contendo três grupos de atividades. Estes contêm uma lista de atividades e a carga horária máxima que pode ser realizada em cada grupo, de forma a totalizar as 200h. Grupo 1 atividades de extensão e ensino; Grupo 2 - atividades acadêmicos- científicos -culturais; Grupo 3 produção acadêmico-científico-cultural e pesquisa institucional vinculada à agência de fomento. O quadro em que se encontram os grupos e a lista de atividades foi colocado no sistema via web ATPA no menu principal no campo "Documentação".

\section{Referências}

ALARCÃO, I. Professores reflexivos em uma escola reflexiva. São Paulo: Cortez, 2010.

BRASIL. Ministério de Educação e do Desporto. Conselho Nacional de Educação/ Conselho Pleno. Resolução CNE/CP 2, de 19 de fevereiro de 2002. Institui a duração 
e a carga horária dos cursos de licenciatura, de graduação plena, de formação de professores da Educação Básica em nível superior. Brasília, DF, 18 fev. 2002. Disponível em: <http://portal.mec.gov.br/cne/arquivos/pdf/CP022002.pdf〉. Acesso em: 20 jun. 2018.

Ministério da Educação. Conselho Nacional de Educação/ Conselho Pleno. Resolução $\mathbf{n}^{\mathbf{0}} \mathbf{2}$ de $\mathbf{1}^{\mathbf{0}}$ de julho de 2015. Brasília-DF, 2015. Disponível em: < http://portal.mec.gov.br/index.php?option=com_docman\&view $=$ download \&alias $=7043$ 1-res-cne-cp-00203072015pdf\&category_slug=agosto-2017-pdf\&Itemid=30192> .

Acesso em: 05 maio 2018.

CLOCK, L. M.; PEREIRA, A. L.; LUCAS, L. B.; MENDES, T. C. Profissão docente no século XXI: concepções do professor sobre o seu papel na sociedade contemporânea. Revista Conjectura: Filosofia e Educação, v. 23, n. 1, p. 77-96, Caxias do Sul: PhilPapers, 2018.

CORRADINI, S. N.; MIZUKAMI, M. G. N. Formação docente: o profissional da sociedade contemporânea. Revista Exitus, v. 1, n. 1, p. 53-62, Pará, 2011. Disponível em: <http://ufopa.edu.br/portaldeperiodicos/index.php/revistaexitus/article/view/205>. Acesso em: 31 mar. 2019.

DOMINGUES, F. R.; VEIGA, A. M. R.; TRINDADE, T. P. Interconexões da gestão pedagógica no moodle e a visão de professores formadores atuantes em licenciaturas. Revista Novas Tecnologias na Educação (RENOTE), v. 15, n. 2, 10 p., dez., 2017.

FRIZON, V.; LAZZARI, M. de B.; SCHWABENLAND, F. P.; TIBOLLA, F. R. C. A. formação de professores e as tecnologias digitais. In: CONGRESSO NACIONAL DE EDUCAÇÃO - EDUCERE, 12., 2015, Curitiba. Anais.... Curitiba: Editora Universitária Champagnat, 2015.

GIL, A. C. Métodos e técnicas de pesquisa social. 5. ed. São Paulo: Atlas S.A., 2008. KENSKI, V. Aprendizagem mediada pela tecnologia. Revista diálogo educacional, $v$. 4, n. 10, 10 p., Paraná, 2003. Disponível em: <http://www.redalyc.org/articulo.oa?id=189118047005>. Acesso em: 31 mar. 2019. PARCIANELLO, L.; KONZEN, P. C. Docência no ensino superior: o uso das novas tecnologias na formação de professores na licenciatura. Arcos, Brasília, Portal Jurídico, p. 01-18, 2011..

SILVA, S. A. P. dos S.; MELO, L. F.; NUNES, H. C. B.; MOURA de, S. Atividades acadêmico-científico-culturais na formação do profissional de Educação Física. Motriz, Revista de Educação Física, v. 18, p. 92-103. Monte Claro-SP, 2012. Disponível em: < http://www.scielo.br/pdf/motriz/v18n1/v18n1a10.pdf>. Acesso em: 02 maio 2018.

SONEGO, A. H. S.; RIBEIRO, A. C. R.; MACHADO, L. R.; BEHAR, P. A.; Formação de professores: uma arquitetura pedagógica com foco na m-learning. Revista Novas Tecnologias na Educação (RENOTE), v. 16, n. 2, 10 p., dezembro, 2018.

SOURCELAB. O que são sistemas web. São Paulo, 2018. Disponível em:< https://sourcelab.com.br/servicos/desenvolvimento-de-sistemas-web/>. Acesso em: 10 ago. 2018.

TARDIF, M. Saberes docentes e formação profissional. Petrópolis: Vozes, 2014.

TOZONI-REIS, M. F. de C. Metodologia da pesquisa. 2. ed. Curitiba: IESDE. 2010.

VALLETTA, D.; BASSO, M. Gênese instrumental e o fenômeno da ubiquidade na formação docente. Revista Novas Tecnologias na Educação (RENOTE), v. 16, n. 1, p1-10, julho 2018. 